\title{
Research and Exploration on the Training Methods of Experimental Ability of Engineering Students in Applied Colleges
}

\author{
Fang Ruan, ${ }^{1,2}$ Hebin Cheng ${ }^{1,2, *}$ \\ ${ }^{1}$ School of Mechatronics, \\ ${ }^{2}$ Key Laboratory of Public Security Management Technology in Universities of Shandong (Shandong Management University) \\ Shandong Management University, \\ 250001 Jinan, China \\ warmmind@163.com
}

\begin{abstract}
At present, such phenomena exist that college students lack active participation in experimental course and attach more importance on the design process instead of test, methods and skills learning. Based on the background of experiment teaching reform, this study pointed out the defects in the experimental process and put forward improving students' cognition in thought and action through a series of initiatives. These initiatives include teacher-student role exchange, assessment methods' change, test ability enhancement, and construction of experimental conditions. To comprehensively enhance the experimental ability of engineering students, these methods play an important role in improving the college students' thinking, practical and innovation abilities.
\end{abstract}

Keywords-Experimental teaching; Talent training; Test method; Innovative thinking

\section{INTRODUCTION}

With the rapid development of electronic information, automation, electrical engineering, communications and other industries, the demand for the talents in such fields is badly increasing. Meanwhile, the technology progress also starves for high requirements of College students. Apart from the excellent theoretical knowledge, solid innovation and practice ability are also required. As a significant link in the teaching activities of higher education in applied colleges, the cultivation of these abilities is the major task to be completed in the experimental teaching of specialized courses, which is helpful for training both practice and innovation abilities of the college students.

Therefore, the cultivation of applied innovative talents must strengthen the experimental teaching link, in which the comprehensive use of knowledge should be attached on high focus to reach the cultivation of innovation consciousness and practical ability. Experiment originates from theory, but it is troublesome for students to combine theory and experimental knowledge together if they barely rely on theory instead of experiment [1]. However, the traditional experimental teaching stressed too much on the theory of teaching, thus leading to lack of attention on the skills learning, cultivation of study interest and creative ability [2].

\section{PROBLEMS IN TRADITIONAL EXPERIMENTAL TEACHING}

\section{A. Less active participation sense of students}

Most of the traditional experiments were taught by the teacher, and the students completed the experiment according to the instructions, in which the disadvantages were obvious. Students were short of subjective thinking; they conducted and completed the experiment step by step in accordance with the teacher's experimental instruction books. In the course of the experiment, they could still finish the experiment and get the result, though without knowledge of the principle and method of the experiment. The students in the whole process of experiment almost got nothing for they were always in a passive and blind position. They just passively completed the experiment, recorded experimental data and wrote test report based on the instruction; this was conducted without access to information, consideration of why each step of the experiment was designed, and understanding of the data and test. Not only the students learned nothing, but the teachers could not receive the students' learning effect either. Despite a lot of experiments, the students' design, testing and debugging abilities were not improved throughout the semester.

\section{B. Students' lack of attention on experiment}

Most universities were putting theory class and experimental teaching in synchronization. They fixed their location and cognition on how to help students strengthen the understanding of theoretical knowledge, the auxiliary role of theoretical teaching, regardless of the complementary relationship between them. In the meantime, the current assessment method has been determined by a large proportion of theoretical courses and small proportion of experimental courses; furthermore the graduate entrance examination only adopted theoretical examination. Improper cognition and the problems led to students' preference of learning theory course to the experiment. Thus they just accomplished in accordance with the experimental instruction; students in experimental course were not serious, randomly completed the experiment, and the plagiarism of the report was severe. 


\section{The divorced prescribed experiment from the scene}

In the experiment process, due to the prescribed steps, students suffered from no troubles and no need of thinking and addressing problems; while in the production and research work on the spot, there were few such linear validation scenarios, therefore the experimental class did not achieve the desired cultivation of students' ability to use knowledge and the modern technology to deal with practical problems. Learning how to test and analyze was conducive to the development of observation, thinking ability and competitiveness of the college students [3].

\section{Simple evaluation method of experimental teaching}

Ordinarily the teacher would give the experimental results according to the experiment report, which was subjective. For the great suspicion experimental report, it cannot demonstrate the true situation of students' experiments, either can it objectively describe the students' situation of experimental operation, the principle mastering and the application.

\section{E. Lack of full-time experimental teachers}

The number of full-time experimental teachers in many schools was small. Experimental teaching was mainly served by the theory teachers, each of whom had to be responsible to more than one class. This posed both the experiment and theory classes on the teachers, and thus their limited time and energy gave a direct impact on the effect of experimental teaching [4].

\section{EXPLORATION ON THE EXPERIMENTAL TEACHING REFORM}

The reform of experimental teaching was based on the reform of ideology, proceeded with the actual operation, and took the improvement of experimental conditions as the backing, and comprehensively reflected the requirements of modern experimental teaching as described below.

\section{A. Initiative replacing passivity}

In the experiment teaching, we took the method of stressing the students' independent study supplemented by teachers' guidance. We employed guiding and suggestive teaching to make the cultivation of autonomous learning ability throughout the experimental teaching.

"Experiment leading" to "experiment guiding" and "teacher centered" to "student-centered" was realized in the teaching. Experimental task books replaced experimental guide books as far as possible. Experimental project generally proposed experimental equipment and requirements, the students made the design scheme, circuit design, device selection, parameters test and results analysis. This could enable them to actively participate in teaching activities, change passive learning to active thinking, possess the space of independent thinking, and arouse their curiosity, imagination and spirit of exploration [5].
The students were required to prepare the relevant contents for the experiment and finish the experiment report of this part. In this process teachers provided extracurricular guidance and inspiration. They adopted a variety of methods to encourage students to complete the experiment and guided them to improve experimental procedures and test methods. After the experiment, the experimental data or the circuit results would be dealt with the software or other tools for data analysis under the teachers' guidance to complete the entire experiment project. Through changing the traditional way of teaching, teachers turn into "the assistant" instead of "the dominant", while students change from "passive receiver" to "active learner", so that students get significant improvement in practical aspects and scientific quality of exercise and experimental design. During the experiment teachers emphasized that students could actively improve consciousness, continuously meet their demands, cultivate their ability of independent experiment, and encourage them to carry on the research and exploration, independent innovation and independent thinking. The students not only demanded for operation and observation, imagination was also needed to mobilize their thinking. They aroused their thinking to draw conclusion from the experiment and explore the problem, and made use of the theory to deal with the accumulation of knowledge and practice.

\section{B. Changing the assessment way of experiment course}

At present, traditional examination mode has three forms, one is attached to the form of theoretical courses and experimental results takes part of theoretical courses with no examination; the second is the independent course form, not belonging to any course; the third is to carry out comprehensive training mode to conduct practical teaching of professional courses. The weakness of the first form lies in that the scores of the experimental class account for less proportion than theory courses, even if the scores of the experimental class are very poor, the overall performance could also be balanced through the theory test ; the second form could fully arise students' attention and get an understanding of students' actual situation. However, some people considered that class independent brought about students' failure to timely combine experiment with theory, which was not conducive to study and cognition of some professional courses. The third way is a comprehensive training generally conducted only after finishing the course to investigate the overall level of the course. Taking the advantages and disadvantages of each method into account, the combination of the first and third assessment is regarded as the optimal solution. It employed the way of examination, but increased the proportion of comprehensive experiment, so that both the theoretical part of the study has been focused and the students' mastery of knowledge is also fully charged. This can develop students' creativity and cultivate students' rigorous scientific attitude and the ability to combine theory with practice and independent working style. 


\section{Changing the students' cognition of the experiments}

Experimental teaching is an important means for training innovative talents, and also a significant part of modern scientific research, especially in scientific research work for science and engineering. In the experimental process, both the early stage of comprehensive investigation and design and the later period of summary report are in favor of the development of innovative design ability. It could help improve their competitiveness, enhance the sense of social responsibility, and master the theoretical knowledge, understanding and application of theoretical knowledge. The experimental teaching is more conducive to building intuition of knowledge structure, promoting their enthusiasm to highlight the exploration research and cultivate students' innovation consciousness and innovation ability. It is beneficial for students to get comprehensive development and innovation. The importance of experiments should be stressed to encourage students to demonstrate the knowledge they learned through experiment. Based on the deepening theoretical knowledge, the students' practice ability and innovation ability could be strengthened.

\section{Systematic study of testing and debugging methods}

In the current experiment, we held the interpretation mainly on the experimental principle and steps, but lacked systematic test method for teaching students, which was very important for students in the future work [6]. Students established a systematic view of scientific research and studied the end to end problem solving ideas. They presented not only design recommendations, but also the corresponding verification method design. It is suggested to increase theoretical study of test methods in the experimental teaching, and verify them in the experiment one by one.

\section{E. Participation in the maintenance of teaching instruments}

In some electronic experiments, most colleges have purchased the experimental toolbox for experimental teaching, which would cause some problems after a period. At present, most colleges adopt the way of direct maintenance by the producer or experimental teachers, but few students participate in maintenance and repair. It is suggested that high grade students that have completed the relevant courses participate in the maintenance of test toolbox. Under the guidance of the teacher, they could complete part of the experimental toolbox testing and maintenance work. This not only helps to get scientific analysis of the circuit and comprehensive use of the knowledge learned to identify errors, but also learns the testing methods, improving the ability of problems solving and analysis. In the usual experimental course, the problems students encountered were usually easy to solve, while the troubles in the experimental toolbox were more complicated, hard to analyze and address. Therefore, through the cooperation with teachers in the maintenance of experimental toolbox, students' test ability and theory analysis capabilities were profoundly improved, which was truly a combination of theory and practice.

\section{F. Strengthening the experimental teachers' ability}

More experimental teachers should be recruited, more training opportunities should be granted, and high education and high grade teachers should be encouraged to carry out the experimental work. Various kinds of welfare treatment should be fulfilled to encourage all aspects of experimental teachers and fully mobilize the enthusiasm of experimental teachers.

\section{G. Improving experimental teaching conditions}

With the continuous progress of science and technology, experimental teaching content should keep pace with the times; some basic content still retains, but the content should be adjusted properly with the current technology development and the most advanced knowledge and technology to broaden their horizons. Thus the appropriate purchase of instruments, the new experimental platform, development board toolbox, and other equipment to support the development of new experimental contents are indispensable.

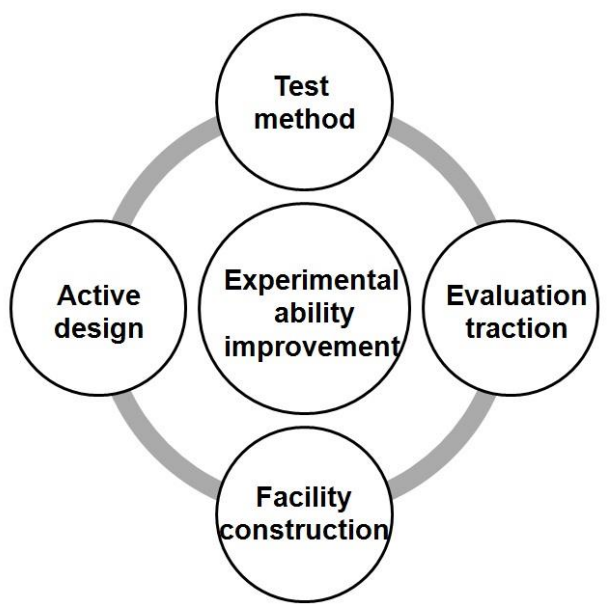

Fig. 1 Schematic illustration of key points for the experimental ability improvement.

\section{H. Constructing the experimental training mode}

In the construction of curriculum system, much attention has been focused on the role and status of the experimental section, while the whole college stage was taken as a whole. The integrity, systematicness and hierarchy of training system should be ensured, the position and function of experimental practice should be definite, emphasizing the application and implementation of the integrated curriculum knowledge system. Therefore, this not only required adjusting the proportion and rhythm in the experimental teaching course construction, but also made full use of outside resources, such as various types of scientific innovation contest, students' organizations, teachers' research projects, college-enterprise cooperation and other activities. Students' comprehensive design, analysis and solving abilities have been cultivated in these innovative activities through a unified inside and outside classroom, which realized the unity of the development of experimental teaching and scientific and technological innovation activities.

In general, the key points of the methods above in actual operation are shown in the Scheme 1. 


\section{CONCLUSION}

Along with the fast technology development, traditional experiment teaching mode needs to take the initiative to adapt to the changing needs of society. We are supposed to reform the traditional teaching ideas to improve the quality of teaching, give full access to students' potential, raise students' practical ability and arouse students' innovation ability. It can be comprehensively conducted and expanded from the curriculum reform, role cognition, teacher construction and other aspects. Through the exploration of the application of digital circuits and other professional courses, students' initiative of experimental courses has been greatly improved, and their thinking and innovative abilities have been enhanced as well. We will constantly continue our research. Only the advanced educational ideas and measures can bring up more suitable students for social development.

\section{ACKNOWLEDGMENT}

This work was financially supported by the Shandong Province Education Science "13th Five-Year" Program (BYGI2017012), Education Reform Project of Shandong Management University (JG2016-22), the Key Laboratory of Public Security Management Technology in Universities of Shandong (Shandong Management University) and 2016 Shandong Undergraduate Colleges and Universities Teaching Reform Research Project.

\section{REFERENCES}

[1] S. Chen and Z. Li, "Strengthening the construction of experimental teaching center and promoting the reform of experimental teaching", Research and Exploration in Laboratory, vol. 29, pp. 114-117, 2010.

[2] K. Zhang, "The reform and innovation of digital circuit experiment teaching”, Laboratory Science, vol. 15, pp. 45-47, 2012.

[3] C. Liu, B. Chen, and J. Wang, "Experimental teaching reform based on the cultivation of students' practice and innovation ability", Science and Technology Innovation Herald, vol. 1, pp. 151-152, 2011.

[4] L. Liang, "Constructing hierarchical experimental teaching system and cultivating innovative talents", Research and Exploration in Laboratory, vol. 33, pp. 217-219, 2014.

[5] L. Liang, "Cultivation of students' innovative ability and experimental teaching reform of Colleges", Journal of Higher Education, vol. 3, pp 114-115, 2017.

[6] Z. Wang, "Cultivation of students' ability in the experimental teaching of electronic information", Research and Exploration in Laboratory, vol. 28 , pp. 94-95, 2009. 